\title{
Ischemic Damage Represents the Main Risk Factor for Biliary Stricture After Liver Transplantation: A Follow-Up Study in a Danish Population
}

\author{
BARBARA LATTANZI ${ }^{1}$, PETER OTT $^{2}$, ALLAN RASMUSSEN $^{3}$, KAREN RABEN KUDSK $^{2}$, \\ MANUELA MERLI ${ }^{1}$ and GERDA ELISABETH VILLADSEN ${ }^{2}$ \\ ${ }^{1}$ Department of Clinical Medicine, Umberto 1 Hospital, Rome, Italy; \\ ${ }^{2}$ Department of Hepatology and Gastroenterology, Aarhus University Hospital, Aarhus, Denmark; \\ ${ }^{3}$ Department of Surgical Gastroenterology and Liver Transplantation, \\ Rigshospitalet, University of Copenhagen, Copenhagen, Denmark
}

\begin{abstract}
Background: Biliary complications (BC) are frequently observed following liver transplantation. The aim of the present retrospective study, conducted at an outpatients' tertiary care hospital, was to determine the incidence of biliary complications and risk factors associated with their development in liver transplantation (lT) patients. Materials and Methods: The medical records were reviewed for all patients who underwent liver transplantation at the Rigshospitalet, Copenhagen, Denmark, from 2000 to 2011 and were referred to the Aarhus University Hospital for follow-up. Patients who died within 3 months of surgery or had incomplete clinical information were excluded. All data for demographic characteristics and possible risk factors for development of biliary stricture were collected. Fifty-one patients were included. Results: The median age at transplantation was 40 (range=7-64) years, and $53 \%$ of patients were males. Biliary complications occurred in 18 patients (35\%), the majority of whom developed strictures (12 patients, 24\%). Univariate and multivariate analyses revealed that cytomegalovirus infection $(p=0.008)$, hepatic artery obstruction $(p=0.03)$ and hepatic artery graft abnormalities $(p=0.03)$ were independent risk
\end{abstract}

This article is freely accessible online.

Correspondence to: Gerda Elisabeth Villadsen, MD, Ph.D., Associate Professor, Department of Hepatology and Gastroenterology, Aarhus University Hospital, Noerrebrogade 44, 8000 C Aarhus, Denmark. Mobile: +45 40414512, e-mail: gerdvill@rm.dk

Key Words: Liver transplantation, biliary complication, strictures, cytomegalovirus, hepatic artery stenosis. factors for the development of biliary strictures. Conclusion: One-third of patients presented biliary complications after liver transplantation, among which biliary strictures were the most common. Cytomegalovirus infection, hepatic artery stenosis and anatomical abnormality of the graft's hepatic artery are independent risk factors for the development of biliary stricture.

Biliary complications (BCs) remain a major problem after liver transplantation $(1,2)$ and are associated with a significant burden of disease. An incidence of BC of 10-25\% has been reported following liver transplantation (LT) from beating-heart donors, and even higher rates in transplantation from non-beating heart donors (3-5). Biliary stricture (BS) represents the most frequently observed post-LT biliary complication. Typically, BSs occur within the first year of LT (5-7), and the reported incidence of this type of complication reportedly ranges from $10-25 \%$ following deceased donor LT to 28-32\% following living donor LT (4, 6-12). BSs are conventionally classified as anastomotic (AS) and non-anastomotic (NAS). While the development of AS is generally related to the surgical technique employed (13), the etiology of NAS is less clear. Ischemic damage is often regarded as the main cause of BS (6, 14-17). Cytomegalovirus (CMV) infection has also been reported to be associated with BS development, possibly mediated by the immunological activation induced by this infection (18).

The incidence of BCs after LT in Denmark is unknown. No previous study has identified the risk factors associated with the development of BCs in a Scandinavian population. Therefore, a study was performed on a group of patients who underwent LT in Denmark to identify incidence of BCs, risk factors associated with BS development and the impact of $\mathrm{BCs}$ and BS on patient survival. 


\section{Materials and Methods}

The medical records were reviewed of all patients that underwent LT at Rigshospitalet in Copenhagen and were referred to Aarhus University Hospital for follow-up from 2000 to 2011. This cohort of patients was followed from the date of transplantation until biliary complication diagnosis, death, or study end (August 15, 2012). Patients who died within 3 months of LT or had incomplete clinical information were excluded. Fifty-one patients were included in this study. For transplant recipients, age, gender, body mass index, liver disease etiology, hepatitis virus $\mathrm{B}$ and $\mathrm{C}$ infection, and presence of hepatocellular carcinoma, diabetes mellitus and arterial hypertension before and after LT were analyzed; for transplant donors, age, gender and mortality due to cerebrovascular accidents were considered. Duration of operation, duration of cold and warm ischemia, type of biliary anastomosis (duct-to-duct anastomosis or hepaticojejunostomy) and presence of anatomical abnormalities of the grafted hepatic artery (HA) were also recorded. Episodes of acute rejection, CMV infection and evidence of HA obstruction (stenosis or thrombosis) were also recorded. After discharge from Rigshospitalet, all patients were followed-up at the outpatient clinic of Aarhus University Hospital.

For patients in whom cholestasis was suspected, the diagnostic approach included an abdominal ultrasound to evaluate the biliary tree and hepatic vasculature followed by a magnetic resonance cholangiopancreatography and angio-computed tomographic scan when required. In the presence of distal BS, an endoscopic retrograde cholangiopancreatography was performed with sphincterotomy and stent placement when indicated. In cases with proximal BS or endoscopic treatment failure, a percutaneous transhepatic cholangiography and stent placement was considered. Stents were changed every 3 months and permanently removed after 1 year. Treatment was defined as successful when cholangiography indicated BS resolution, cholestasis was ameliorated, and symptoms were resolved. BS was diagnosed when stenosis of the bile duct was observed on imaging in the presence of biochemical cholestasis with or without clinical symptoms. AS was diagnosed in the presence of a stenosis at the anastomotic level. Strictures, dilatations or irregularities of the intra-and extrahepatic bile ducts, excluding the site of anastomosis, were classified as NAS.

Statistical analysis. Categorical variables are reported as the number and percentage of cases, and Pearson Chi-square and Fisher's exact tests were used for their comparisons. Continuous variables are reported as medians. Student $t$-test was used for comparing continuous variables with Gaussian distributions, while MannWhitney $U$-tests were adopted for variables with skewed distributions. Differences with $p$-values of less than 0.05 indicated statistical significance. Initially, univariate logistic regression analyses were performed to identify risk factors for the development of BS. Subsequent multivariate logistic regression analysis was performed including only variables with values of $p<0.1$ in the univariate analyses. Risk prediction estimates are reported as $p$ values, odds ratios (OR), and 95\% confidence intervals (95\% CI). Patient and graft survival rates were analyzed using the KaplanMeier method and compared using the log-rank test. Statistical analyses were performed and plots were generated using NCSS 2007 (NCSS, Chicago, IL, USA).
Table I. Clinical and biochemical characteristics of the study population $(n=51)$.

\begin{tabular}{lc}
\hline Variable & Value \\
\hline Median recipient age (range), years & $40(7-64)$ \\
Male gender, $\mathrm{n}(\%)$ & $27(52.9 \%)$ \\
Liver disease etiology, n (\%) & \\
PSC & $11(21.6 \%)$ \\
Amyloidosis & $7(13.7 \%)$ \\
Fulminant hepatitis & $7(13.7 \%)$ \\
Autoimmune hepatitis & $5(9.8 \%)$ \\
PBC & $5(9.8 \%)$ \\
Viral & $3(5.9 \%)$ \\
Alcoholic & $3(5.9 \%)$ \\
Other & $10(19.6 \%)$ \\
Acute rejection, n (\%) & $15(30 \%)$ \\
CMV infection, $\mathrm{n}(\%)$ & $10(20 \%)$ \\
Pre-LT AX, n (\%) & $7(14 \%)$ \\
Post-LT AX, n (\%) & $13(25.5 \%)$ \\
Pre-LT DM, $\mathrm{n}(\%)$ & $5(9.8 \%)$ \\
Post-LT DM, n (\%) & $10(19.6 \%)$ \\
Duct-to-duct anastomosis, $\mathrm{n}(\%)$ & $36(70.6 \%)$ \\
Median follow-up (range), months & $52.8(3.3-147.6)$ \\
\hline
\end{tabular}

PSC, Primary sclerosing cholangitis; AX, arterial hypertension; CMV, cytomegalovirus; DM, diabetes mellitus; LT, liver transplantation.

Table II. Types and presentations of biliary complication in study patients $(n=51)$.

\begin{tabular}{lc}
\hline Biliary complication & Frequency, n (\%) \\
\hline All biliary complications & $18(35.3 \%)$ \\
Stricture & $15(29.4 \%)$ \\
AS & $6(11.7 \%)$ \\
NAS & $5(9.8 \%)$ \\
AS and NAS & $4(7.8 \%)$ \\
Biloma & $1(1.9 \%)$ \\
Leakage & $3(5.8 \%)$ \\
\hline
\end{tabular}

AS: Anastomotic stricture; NAS: non-anastomotic stricture.

\section{Results}

The medical records were reviewed of 51 liver recipients with a median follow-up of 53 months. The clinical and demographic characteristics of patients are reported in Table I. For surgical team policy, none of the patients had a T-tube placed after transplantation. Biliary complications occurred in 18 patients $(35.3 \%)$. The most common complications were strictures (15 patients, 29\%). Of the patients with BS, six $(40 \%)$ developed AS, five $(33 \%)$ NAS and four $(27 \%)$ both stricture types. The median time from LT to BS diagnosis was 7.8 months (range=0.1-84.2 months). In seven 
Table III. Univariate analysis of risk factors for the development of biliary stricture (BS).

\begin{tabular}{|c|c|c|c|}
\hline Variable & With BS $(n=15)$ & Without BS (n=36) & $p$-Value \\
\hline \multicolumn{4}{|l|}{ Recipient-related } \\
\hline Recipient age (years) & $40(28-52)$ & $43(37-50)$ & 0.700 \\
\hline Male gender, n (\%) & $6(40 \%)$ & $21(51.3 \%)$ & 0.200 \\
\hline \multicolumn{4}{|l|}{ Liver disease etiology, n (\%) } \\
\hline $\mathrm{PBC}$ & $2(13.3 \%)$ & $3(8.3 \%)$ & 0.500 \\
\hline PSC & $4(26.7 \%)$ & $7(19.4 \%)$ & 0.500 \\
\hline Alcohol & 0 & $3(8.3 \%)$ & 0.300 \\
\hline Fulminant hepatitis & $2(13.3 \%)$ & $5(13.9 \%)$ & 0.900 \\
\hline Autoimmune hepatitis & $2(13.3 \%)$ & $3(8.3 \%)$ & 0.400 \\
\hline Amyloidosis & $2(13.3 \%)$ & $5(13.9 \%)$ & 0.900 \\
\hline Viral & $1(6.8 \%)$ & $2(5.6 \%)$ & 0.800 \\
\hline Other & $2(13.3 \%)$ & $8(22.3 \%)$ & 0.300 \\
\hline Duct-to-duct anastomosis, n (\%) & $11(73.3 \%)$ & $25(69.4 \%)$ & 0.200 \\
\hline Episode of acute rejection, $\mathrm{n}(\%)$ & $6(40 \%)$ & $11(30.5 \%)$ & 0.600 \\
\hline Cytomegalovirus infection, $\mathrm{n}(\%)$ & $6(40 \%)$ & $3(8.3 \%)$ & 0.008 \\
\hline HAS, n (\%) & $6(40 \%)$ & $4(11.1 \%)$ & 0.030 \\
\hline Transplant performed after 2006 & $9(60 \%)$ & $21(58.3 \%)$ & 0.900 \\
\hline Duration of hospitalization (days) & $30(21-60)$ & $21(20-31)$ & 0.100 \\
\hline \multicolumn{4}{|l|}{ Donor-related } \\
\hline Median age (range), years & $48.5(38-55)$ & $47(36-53)$ & 0.300 \\
\hline Median BMI (range), kg/m2 & $23.3(21.7-26.2)$ & $23.8(22-26)$ & 0.900 \\
\hline Mortality due to CVA, n (\%) & $11(73 \%)$ & $19(53 \%)$ & 0.250 \\
\hline \multicolumn{4}{|l|}{ Surgical-related } \\
\hline Abnormalities of graft HA n (\%) & $4(26.6 \%)$ & $2(5.5 \%)$ & 0.030 \\
\hline Use of University of Wisconsin solution, $\mathrm{n}(\%)$ & $5(33 \%)$ & $11(31 \%)$ & 0.600 \\
\hline Median duration of biliary anastomosis packing (range), min & $20(15-35)$ & $20(15-26)$ & 0.800 \\
\hline Hepaticojejunostomy as anastomosis & $4(27 \%)$ & $11(31 \%)$ & 0.800 \\
\hline Median duration of surgery (range), $\mathrm{h}$ & $6.50(5.30-7.12)$ & $6.40(6.13-7.20)$ & 0.500 \\
\hline Median duration of cold ischemia (range), $\mathrm{h}$ & $10.50(8.20-13)$ & $10.46(8-13)$ & 0.800 \\
\hline Median duration of warm ischemia (range), min & $55(43-59)$ & $52(40-55)$ & 0.460 \\
\hline Median duration of total ischemia (range), $\mathrm{h}$ & $11.6(8.58-14.3)$ & $11.5(9.38-13.5)$ & 0.900 \\
\hline
\end{tabular}

ALAT: Alanine aminotransferase; BAP: basic phosphatase; Bil Tot: total bilirubin; GGT: gamma-glutamyl transferase; HA(S): hepatic artery (stenosis); PBC: primary biliary cirrhosis; PSC: primary sclerosing cholangitis.

cases $(47 \%)$, BS diagnosis was made within 6 months of LT, and in eight cases $(53 \%)$ within 1 year. The types and presentations of biliary complications are reported in Table II. The Kaplan-Meier plot (log-rank test) showed no difference in patient or graft survival between patients with and without BSs ( $p$-values of 0.9 and 0.9 , respectively).

Risk factors for the development of BS. In the univariate analyses, CMV infection, HA obstruction (stenosis or thrombosis) and anatomical abnormalities of the grafted HA were associated with the development of BS. Duration of cold and warm ischemia, duration of operation, episodes of rejection and donor age were not significantly associated with the development of BS (Table III). In the multivariate analysis, $\mathrm{CMV}$ infection $(\mathrm{OR}=6.5 ; p=0.028)$, anatomical abnormalities of the grafted HA $(\mathrm{OR}=8.4 ; p=0.042)$ and HA obstruction $(\mathrm{OR}=7.4 ; p=0.048)$ appeared to be independent risk factors for the development of BS (Table IV).
Table IV. Multivariate analysis (logistic regression) of significant risk factors for biliary stricture.

\begin{tabular}{lccc}
\hline Variable & OR & $95 \%$ CI & $p$-Value \\
\hline HA obstruction & 7.4 & $1.16-47.35$ & 0.048 \\
Graft HA abnormality & 8.4 & $1.02-72.03$ & 0.042 \\
CMV infection & 6.5 & $1.01-44.9$ & 0.028 \\
\hline
\end{tabular}

HA: Hepatic artery; CMV cytomegalovirus; CI: confidence interval; OR: odds ratio.

\section{Discussion}

Despite continuous progress in the field of LT (19), biliary complications still affect a considerable number of LT patients $(3,4,20)$. In our study, we confirmed the presence of a high $\mathrm{BC}$ incidence in a Danish population. Overall, $35 \%$ of LT 
patients developed BCs, among which BSs were the most common, developing in $29.4 \%$ of patients. These rates were comparable with those reported in other studies conducted in similar populations $(6,7,21,22)$. However, lower rates have also been reported in some series $(2,23)$. These discrepancies may be explained by differences in the definitions of BCs, imaging techniques utilized for surveillance of BS and duration of follow-up (24). As also reported previously, in our series, BCs most often developed within 1 year of LT $(6,7)$. The development of BSs after LT has previously been reported to be associated with risk factors closely linked to ischemia, such as long ischemia time, reperfusion injury and HA thrombosis and stenosis (25-27). CMV infection and surgical technique have also previously been correlated with BS development $(14,28)$. In addition, recent studies have suggested that 'marginal donor characteristics' such as donor age and macrovesicular steatosis of the graft may also be important in this context $(21,29,30)$.

In our study, we confirmed previous findings suggesting that HA stenosis and thrombosis were risk factors for the development of biliary strictures (31-34). Moreover, we observed a correlation between anatomical abnormalities of the grafted HA and BS development, which may also be related to ischemic damage to the biliary tree. The biliary tree may be especially vulnerable to a reduction in arterial blood flow from the HA; in fact, vascular supply to the allograft biliary system is maintained by a unique HA terminating in the peribiliary vascular plexus $(16,35,36)$. The low number of included patients did not allow a separate analysis of risk factors associated with AS and NAS to be performed.

We confirmed the previously suggested association between CMV infection and BS development (14). The mechanism due to this association is likely immunological. CMV is known to be a potent up-regulator of alloantigens, thereby increasing the risk of acute rejection and chronic allograft dysfunction; these mechanisms may be linked to the development of vanishing bile duct syndrome and ductopenic rejection, leading to chronic cholestasis and, eventually, allograft failure $(17,37-40)$.

In contrast to the results of previous studies, we did not identify any association between the duration of warm or cold ischemia and the development of BS; neither did we observe associations between either recipient gender or age and the onset of this type of complication. However, it should be noted that the mean recipient age in our study population did not exceed 48 years. It has been suggested that the peribiliary vascular plexus is better flushed out and better preserved when low-viscosity rather than highviscosity fluids are used $(41,42)$. However, to our knowledge, these observations have not yet been confirmed in randomized control trials, and in our series, no association was observed between the incidence of BS and the type of preservation fluid utilized. Moreover, the biliary anastomosis technique employed did not seem to play a role in the onset of BS; in fact, no difference was observed between patients who underwent duct-to-duct anastomosis and those who underwent a hepaticojejunostomy. Although previous studies have shown a shorter survival time in patients with BC (43), we observed no differences in patient or graft survival, which is in accordance with the findings of recent reports (21, 44, 45). Early detection of BSs and therapeutic intervention improvement in radiology or endoscopy may easily explain these results (46).

The present study has certain limitations. Firstly, it was a retrospective study, and the use of this methodology limited our ability to comprehensively collect data for all variables potentially influencing BS development, such as median blood loss and graft steatosis frequency, as these data were not available. Secondly, the small number of patients with AS and NAS prevented us from performing separate analyses focusing on these patient subgroups.

In conclusion, based on the results of our study, BSs still represent an important complication in LT patients, and the main mechanism involved in their development appears to be ischemic damage. Immunological damage mediated by CMV infection may also be involved in the onset of this complication.

\section{References}

1 Calne RY: A new technique for biliary drainage in orthotopic liver transplantation utilizing the gall bladder as a pedicle graft conduit between the donor and recipient common bile ducts. Ann Surg 184: 605-609, 1976.

2 Nemes B, Gámán G and Doros A: Biliary complications after liver transplantation. Expert Rev Gastroenterol Hepatol 9: 447466, 2015.

3 Wojcicki M, Milkiewicz $\mathrm{P}$ and Silva M: Biliary tract complications after liver transplantation: a review. Dig Surg 25: 245-257, 2008.

4 Kobayashi N, Kubota K, Shimamura T, Watanabe S, Kato S, Suzuki K, Uchiyama T, Maeda S, Takeda K, Nakajima A and Endo I: Complications of the treatment of endoscopic biliary strictures developing after liver transplantation. J Hepatobiliary Pancreat Sci 18: 202-210, 2011.

5 Ayoub WS, Esquivel CO and Martin P: Biliary complications following liver transplantation. Dig Dis Sci 55: 1540-1546, 2010.

6 Pirenne J, Monbaliu D, Aerts R, Desschans B, Liu Q, Cassiman D, Laleman W, Verslype C, Magdy M, Van Steenbergen W and Nevens F: Biliary strictures after liver transplantation: Risk factors and prevention by donor treatment with epoprostenol. Transplant Proc 41: 3399-3402, 2009.

7 Chang JH, Lee IS, Choi JY, Yoon SK, Kim DG, You YK, Chun HJ, Lee DK, Choi MG and Chung IS: Biliary stricture after adult right-lobe living-donor liver transplantation with duct-to-duct anastomosis: long-term outcome and its related factors after endoscopic treatment. Gut Liver 4: 226-233, 2010.

8 Sawyer RG and Punch JD: Incidence and management of biliary complications after 291 liver transplants following the introduction of transcystic stenting. Transplantation 66: 12011207, 1998. 
9 Yersiz H, Renz JF, Farmer DG, Hisatake GM, McDiarmid SV and Busuttil RW: One hundred in situ split-liver transplantations: a single-center experience. Ann Surg 238: 496-505, 2003.

10 Gondolesi GE, Varotti G, Florman SS, Muñoz L, Fishbein TM, Emre SH, Schwartz ME and Miller C: Biliary complications in 96 consecutive right lobe living donor transplant recipients. Transplantation 77: 1842-1848, 2004.

11 Thethy S, Thomson BNj, Pleass H, Wigmore SJ, Madhavan K, Akyol M, Forsythe JL and James Garden O: Management of biliary tract complications after orthotopic liver transplantation. Clin Transplant 18: 647-653, 2004.

12 Graziadei IW, Schwaighofer H, Koch R, Nachbaur K, Koenigsrainer A, Margreiter $\mathrm{R}$ and Vogel W: Long-term outcome of endoscopic treatment of biliary strictures after liver transplantation. Liver Transpl 12: 718-725, 2006.

13 Verdonk RC, Buis CI, Porte RJ, van der Jagt EJ, Limburg AJ, van den Berg AP Slooff MJ, Peeters PM, de Jong KP, Kleibeuker JH and Haagsma EB: Anastomotic biliary strictures after liver transplantation: causes and consequences. Liver Transpl 12: 726735, 2006

14 Buis CI, Verdonk RC, Van der Jagt EJ, van der Hilst CS, Slooff MJ, Haagsma EB and Porte RJ: Nonanastomotic biliary strictures after liver transplantation, part 1: Radiological features and risk factors for early vs. late presentation. Liver Transpl 13: 708-718, 2007.

15 Cho KJ and Lunderquist A: The peribiliary vascular plexus: the microvascular architecture of the bile duct in the rabbit and in clinical cases. Radiology 147: 357-364, 1983.

16 Sibulesky L and Nguyen JH: Update on biliary strictures in liver transplants. Transplant Proc 43: 1760-1764, 2011.

17 Jiang T, Li C, Duan B, Liu Y, Wang L and Lu S: Risk factors for and management of ischemic-type biliary lesions following orthotopic liver transplantation: A single-center experience. Ann Hepatol 15: 41-46, 2016.

18 Hsu HY, Chang MH, Ni YH and Huang SF: Cytomegalovirus infection and proinflammatory cytokine activation modulate the surface immune determinant expression and immunogenicity of cultured murine extrahepatic bile duct epithelial cells. Clin Exp Immunol 126: 84-91, 2001.

19 Shiffman ML, Saab S, Feng S, Abecassis MI, Tzakis AG, Goodrich NP and Schaubel DE: Liver and intestine transplantation in the United States 1995-2004. Am J Transplant 6: 1170-1187, 2006.

20 Kienlein S, Schoening W, Andert A, Kroy D, Neumann UP and Schmeding M: Biliary complications in liver transplantation: Impact of anastomotic technique and ischemic time on short-and long-term outcome. World J Transplant 5: 300-309, 2015.

21 Lattanzi B, Lai Q, Guglielmo N, Giannelli V, Merli M, Giusto M, Melandro F, Ginanni Corradini S, Mennini G, Berloco PB and Rossi M: Graft macrosteatosis and time of T-tube removal as risk factors for biliary strictures after liver transplantation. Clin Transplant 27: E332-338, 2013.

22 Senter-Zapata M and Khan AS, Subramanian T, Vachharajani N, Dageforde LA, Wellen JR, Shenoy S, Majella Doyle MB and Chapman WC: Patient and graft survival: biliary complications after liver transplantation. J Am Coll Surg 226: 484-494, 2018.

23 Zimmerman MA, Baker T, Goodrich NP, Freise C, Hong JC, Kumer S, Abt P, Cotterell AH, Samstein B, Everhart JE and
Merion RM: Development, management, and resolution of biliary complications after living and deceased donor liver transplantation: a report from the adult-to-adult living donor liver transplantation cohort study consortium. Liver Transpl 19: 259-2567, 2013.

24 Gastaca M, Matarranz A, Muñoz F, Valdivieso A, Aguinaga A, Testillano M Bustamante J, Terreros I, Suarez MJ, Montejo M and Ortiz de Urbina J: Biliary complications in orthotopic liver transplantation using choledochocholedochostomy with a T-tube. Transplant Proc 44: 1554-1556, 2012.

25 Guichelaar MM, Benson JT, Malinchoc M, Krom RA, Wiesner RH and Charlton MR: Risk factors for and clinical course of non-anastomotic biliary strictures after liver transplantation. Am J Transplant 3: 885-890, 2003.

26 Park JB, Kwon CH, Choi GS, Chun JM, Jung GO, Kim SJ, Joh JW and Lee SK: Prolonged cold ischemic time is a risk factor for biliary strictures in duct-to-duct biliary reconstruction in living donor liver transplantation. Transplantation 86: 15361542, 2008.

27 Welling TH, Heidt DG, Englesbe MJ, Magee JC, Sung RS, Campbell DA, Punch JD and Pelletier SJ: Biliary complications following liver transplantation in the model for end-stage liver disease era: effect of donor, recipient, and technical factors. Liver Transpl 14: 73-80, 2008.

28 Weiss S, Schmidt SC, Ulrich F, Pascher A, Schumacher G, Stockmann M, Puhl G, Guckelberger O, Neumann UP, Pratschke $\mathrm{J}$ and Neuhaus P: Biliary reconstruction using a side-to-side choledochocholedochostomy with or without T-tube in deceased donor liver transplantation: a prospective randomized trial. Ann Surg 250: 766-771, 2009.

29 Shah SA, Levy GA, Greig PD, Smith R, McGilvray ID, Lilly LB, Girgrah N, Cattral MS and Grant DR: Reduced mortality with right-lobe living donor compared to deceased-donor liver transplantation when analyzed from the time of listing. Am J Transplant 7: 998-1002, 2007.

30 Baccarani U, Isola M, Adani GL, Avellini C, Lorenzin D, Rossetto A Currò G, Comuzzi C, Toniutto P, Risaliti A, Soldano F, Bresadola V, De Anna D and Bresadola F: Steatosis of the hepatic graft as a risk factor for post-transplant biliary complications. Clin Transplant 24: 631-635, 2010.

31 Tzakis AG: The dearterialized liver graft. Semin Liver Dis 5: 375-376, 1985.

32 Lerut JP, Gordon RD, Iwatsuki S and Starzl TE: Human orthotopic liver transplantation: surgical aspects in 393 consecutive grafts. Transplant Proc 20: 603-606, 1988.

33 Margarit C, Hidalgo E, Lázaro JL, Murio E, Charco R and Balsells J: Biliary complications secondary to late hepatic artery thrombosis in adult liver transplant patients. Transpl Int 11: S251-254, 1998.

34 Verdonk RC, Buis CI, Porte RJ and Haagsma EB: Biliary complications after liver transplantation: a review. Scand J Gastroenterol Suppl 243: 89-101, 2006.

35 Northover JM and Terblanche J: A new look at the arterial supply of the bile duct in man and its surgical implications. $\mathrm{Br}$ J Surg 66: 379-384, 1979.

36 Demetris AJ, Jaffe R, Tzakis A, Ramsey G, Todo S, Belle S, Esquivel C, Shapiro R, Markus B and Mroczek E: Antibodymediated rejection of human orthotopic liver allografts. A study of liver transplantation across ABO blood group barriers. Am J Pathol 132: 489-502, 1988. 
37 Ludwig J, Wiesner RH, Batts KP, Perkins JD and Krom RA: The acute vanishing bile duct syndrome (acute irreversible rejection) after orthotopic liver transplantation. Hepatology 7: 476-483, 1987.

38 O'Grady JG, Alexander GJ, Sutherland S, Donaldson PT, Harvey F, Portmann B, Calne RY and Williams R: Cytomegalovirus infection and donor/recipient HLA antigens: Interdependent co-factors in pathogenesis of vanishing bile-duct syndrome after liver transplantation. Lancet 2: 302-5, 1988.

39 Noack KB, Wiesner RH, Batts K, van Hoek B and Ludwig J: Severe ductopenic rejection with features of vanishing bile duct syndrome: clinical, biochemical, and histologic evidence for spontaneous resolution. Transplant Proc 23: 1448-1451, 1991.

40 Razonable RR and Paya CV: Infections and allograft rejectionintertwined complications of organ transplantation. Swiss Med Wkly 135: 571-573, 2005.

41 Canelo R, Hakim NS and Ringe B: Experience with hystidine tryptophan ketoglutarate versus University Wisconsin preservation solutions in transplantation. Int Surg 88: 145-151, 2003.

42 Cavallari A, Cillo U, Nardo B, Filipponi F, Gringeri E, Montalti R, Vistoli F, D'amico F, Faenza A, Mosca F, Vitale A and D'Amico D: A multicenter pilot prospective study comparing Celsior and University of Wisconsin preserving solutions for use in liver transplantation. Liver Transpl 9: 814-821, 2003.
43 Khuroo MS, Al Ashgar H, Khuroo NS, Khan MQ, Khalaf HA, Al-Sebayel M and El Din Hassan MG: Biliary disease after liver transplantation: the experience of the King Faisal Specialist Hospital and Research Center, Riyadh. J Gastroenterol Hepatol 20: 217-228, 2005

44 Dorobantu B, Brasoveanu V, Matei E, Dima S, Giacomoni A, Slim A, Lauterio A, Forti D, Popescu I and De Carlis L: Biliary complications after liver transplantation-523 consecutive cases in two centers. Hepatogastroenterology 57: 932-938, 2010.

45 Sundaram V, Jones DT, Shah NH, de Vera ME, Fontes P, Marsh JW, Humar A and Ahmad J: Posttransplant biliary complications in the pre-and post-model for end-stage liver disease era. Liver Transpl 17: 428-435, 2011.

46 Shin M and Joh JW: Advances in endoscopic management of biliary complications after living donor liver transplantation: Comprehensive review of the literature. World J Gastroenterol 22: 6173-6191, 2016.
Received July 7, 2018

Revised August 3, 2018

Accepted August 6, 2018 